\title{
Congenital pseudoarthrosis in a child with neurofibromatosis
}

\author{
Kathryn Stammers, ${ }^{1}$ Simon Cope $^{2}$
}

${ }^{1}$ Department of Trauma and Orthopaedics, East and North Herts NHS Trust, Stevenage, UK

${ }^{2}$ Torbay Hospital, Torquay, UK

\section{Correspondence to}

Dr Kathryn Stammers, kathrynstammers90@gmail. com

Accepted 19 November 2015

\section{DESCRIPTION}

A 4-year-old girl with neurofibromatosis type 1 (NF-1) was admitted to the emergency department, with a left-sided limp and pain. A detailed history was taken and there was no suspicion of physical abuse. Examination revealed a varus deformity of the left leg, which was $5 \mathrm{~cm}$ shorter than the right. Anteroposterior X-rays revealed distal tibia and fibula fractures (figure 1) with associated pseudarthrosis and a radiolucent lesion on the tibial shaft (figure 2). There had been bowing of the tibia since birth (figure 3). These unilateral findings are indicative of congenital pseudoarthrosis of the tibia (CPT), a condition that may co-exist alongside NF-1 in $50 \%$ of cases. ${ }^{1}$ The reported incidence of CPT varies between 1:140000 and 1:250 000. ${ }^{2}$ The tibia shows an area of segmental dysplasia resulting in bowing of the bone. The osseous dysplasia leads to tibial non-union and, because of tibial bowing and reduced growth in the distal tibial epiphysis, shortening of the limb usually

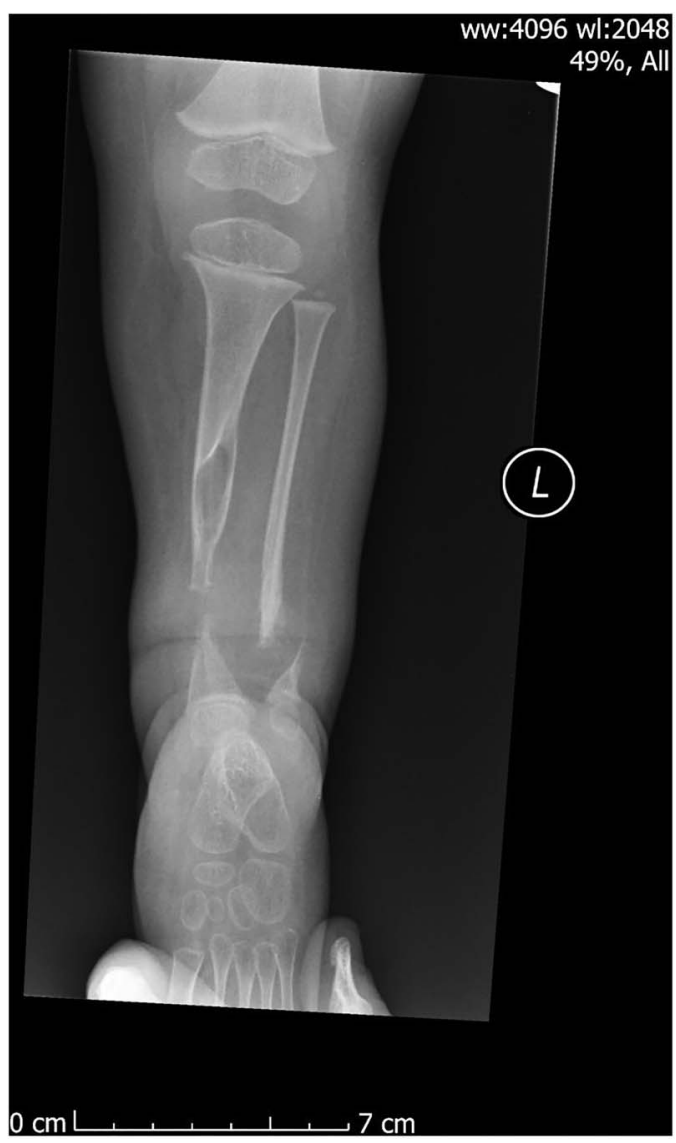

Figure 1 X-ray showing distal fractures of the tibia and fibula, with associated pseudoarthroses. There is a lucent lesion in the tibia, superior to the fracture.

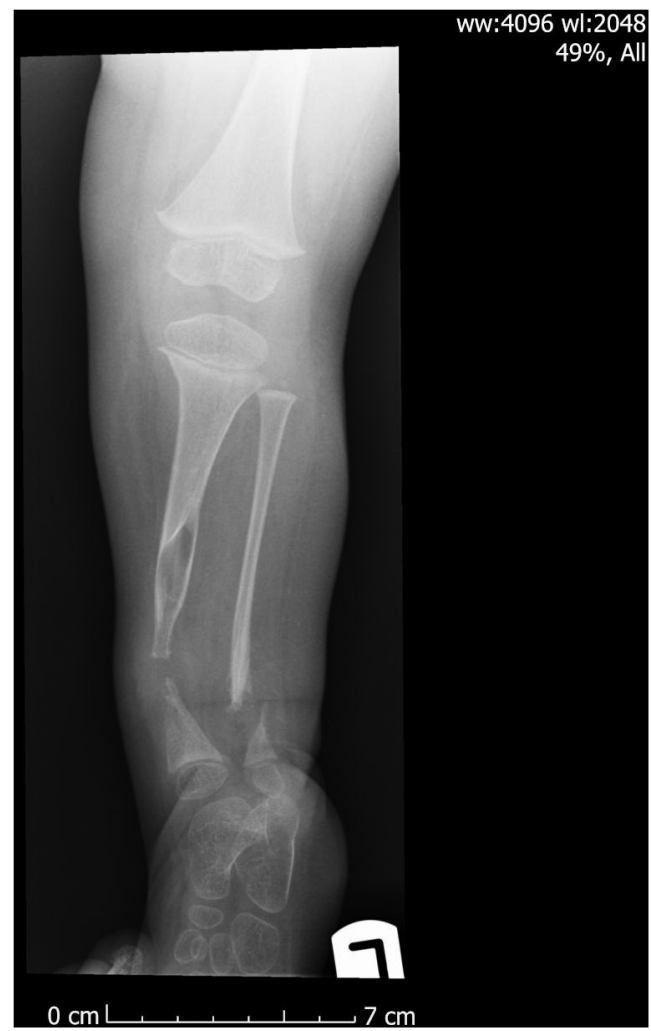

Figure 2 A further X-ray demonstrating the tibial pseudoarthrosis.

occurs. ${ }^{2}$ The best treatment for CPT remains controversial, however, conservative management was initially recommended in this case. Surgery may be indicated in the future, using Llizarov's technique, and further osteotomies may be required. However, often there is controversy about the timing of when to operate. On reviewing previous $\mathrm{X}$-rays, an area

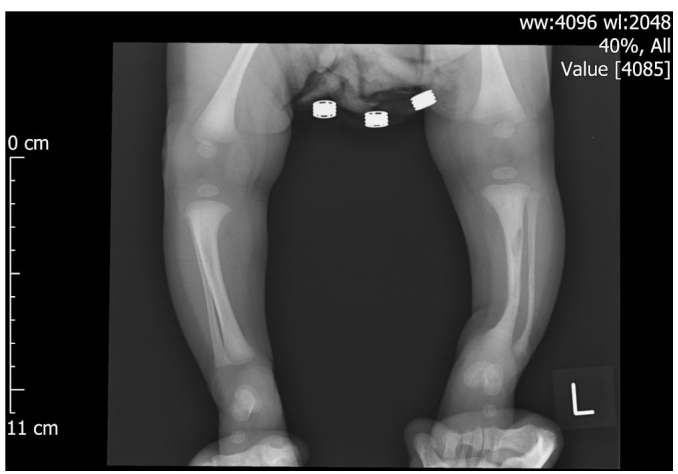

Figure 3 There was bowing of the left tibia and fibula from the age of 1 month of age, although no evidence of pseudoarthrosis. 
of pseudoarthrosis was apparent from the age of 1 year. Since diagnosis, the patient was advised to mobilise with a leg splint and wear an orthotic insole to reduce leg length discrepancy. Prophylactic bracing with a knee-ankle-foot orthosis is often advocated in the early stages before the child starts walking, to

\section{Learning points}

- Other conditions that can present as pathological bone fractures in the paediatric population include: infection, rickets, benign tumours (non-ossifying fibroma and osteochondroma), malignant tumours (Ewing's sarcoma, leucaemia, fibrosarcomas and osteosarcoma). In the case of multiple fractures, osteogenesis imperfecta should be considered.

- If non-accidental injury is suspected, there needs to be clear documentation, with detailed history-taking and thorough examination performed. Physicians should follow the safeguarding protocol.

- An appreciation and awareness of congenital pseudoarthrosis of the tibia should allow physicians to accurately diagnose and manage this condition successfully, and refer to the relevant specialists. prevent progression to fracture, and is often worn until skeletal maturity. ${ }^{2}$ Unfortunately, half the cases of congenital anterior bowing of the tibia associated with neurofibromatosis will suffer a fracture, which always results in a pseudoarthrosis, in the first year of life. ${ }^{3}$ This case highlights the need for other differentials to be considered including non-accidental injury (NAI), metabolic bone disease, connective tissue disease and tumours. It is important to be aware that fractures can occur in a significant amount of child abuse cases. Therefore in all cases, careful history-taking and thorough examination are needed. If there is any suspicion of NAI, safeguarding protocol should be followed.

Contributors KS helped manage and treat the patient, and SC supervised and had overall responsibility for the patient. Written by KS and edited by SC.

Competing interests None declared.

\section{Patient consent Obtained.}

Provenance and peer review Not commissioned; externally peer reviewed.

\section{REFERENCES}

1 Berber R, Berber O, Taguri N, et al. Pseudarthrosis of the tibia: emergency department presentation of neurofibromatosis type 1 in a 4-month-old infant. Emerg Med J 2009;26:306-7.

2 Shah $\mathrm{H}$, Rousset M, Canavese F. Congenital pseudarthrosis of the tibia: management and complications. Indian J Orthop 2012;46:616-26.

3 Strong ML, Wong-Chung J. Prophylactic bypass grafting of the prepseudoarthrotic tibia in neurofibromatosis. J Pediatr Orthop 1991;11:757-64.

Copyright 2015 BMJ Publishing Group. All rights reserved. For permission to reuse any of this content visit http://group.bmj.com/group/rights-licensing/permissions.

BMJ Case Report Fellows may re-use this article for personal use and teaching without any further permission.

Become a Fellow of BMJ Case Reports today and you can:

- Submit as many cases as you like

- Enjoy fast sympathetic peer review and rapid publication of accepted articles

- Access all the published articles

- Re-use any of the published material for personal use and teaching without further permission

For information on Institutional Fellowships contact consortiasales@bmjgroup.com

Visit casereports.bmj.com for more articles like this and to become a Fellow 